\title{
Epidemiology of Plasmodium falciparum Malaria and Risk Factors for Severe Disease in Hubei Province, China
}

\author{
Jing Xia, ${ }^{1}$ Dongni Wu, ${ }^{1}$ Kai Wu, ${ }^{2}$ Hong Zhu, ${ }^{1}$ Lingcong Sun, ${ }^{1}$ Wen Lin, ${ }^{1}$ Kaijie Li, ${ }^{1}$ Juan Zhang,,${ }^{1}$ Lun Wan, ${ }^{1}$ \\ Huaxun Zhang, ${ }^{1 \star}$ and Si Liu ${ }^{1 *}$ \\ ${ }^{1}$ Institute of Schistosomiasis Control, Hubei Provincial Center for Disease Control and Prevention, Wuhan, China; ${ }^{2}$ Department of Schistosomiasis \\ and Endemic Diseases, Wuhan City Center for Disease Prevention and Control, Wuhan, China
}

\begin{abstract}
This study aimed to describe the epidemiology of Plasmodium falciparum malaria and identify risk factors for severe disease in Hubei Province, China, using a case-based survey of retrospective data from 2013 to 2018 . From 2013 to 2018, a total of 763 imported malaria cases were reported in Hubei Province; $69.2 \%$ (528/763) cases were caused by $P$. falciparum species. The proportion of malaria caused by $P$. falciparum increased from $66.7 \%$ in 2013 to $74.0 \%$ in $2018\left(x^{2}=21.378, P<0.05\right)$. Plasmodium falciparum malaria was reported in 77 counties of Hubei Province. The majority of imported $P$. falciparum cases originated from Africa (98.9\%, 522/528); 9.7\% (51/528) of patients infected with $P$. falciparum developed severe malaria. Three deaths (case fatality rate: $0.6 \%$ ) were related to imported $P$. falciparum malaria. Risk factors for severe malaria were being female (odds ratio [OR] $=3.593,95 \% \mathrm{Cl}: 1.003-12.874$ ), age $\geq 50$ years $(\mathrm{OR}=2.674,95 \% \mathrm{Cl}: 1.269-5.634)$, > 3 days between symptom onset and diagnosis (OR = 2.383, 95\% Cl: $1.210-4.693)$, and the first-visit medical institution at the township level or lower $(\mathrm{OR}=2.568,95 \% \mathrm{Cl}: 1.344-4.908)$. Malaria prevention should be undertaken among high-risk groups, infection with $P$. falciparum should be detected early to prevent severe disease and death, and healthcare providers in health facilities at the township level should be trained on early recognition of malaria.
\end{abstract}

\section{INTRODUCTION}

Malaria is one of the most common parasitic diseases in the world. According to the latest global estimates, in 2018, there were 228 million cases of malaria and 405,000 deaths. ${ }^{1}$ Infection with Plasmodium falciparum species is the most common cause of severe malaria. ${ }^{2}$ Importation of $P$. falciparum from endemic areas remains a challenge for malaria-free countries and countries working toward eliminating malaria. According to the WHO, $2-16 \%$ of imported $P$. falciparum infections caused severe malaria. ${ }^{3}$ With China working toward malaria elimination in 2020 , no indigenous cases have been reported since $2017 .{ }^{4}$ However, the number of imported malaria cases in China has increased. Of 26,601 cases reported between 2011 and 2018, 93\% were imported, with P. falciparum accounting for the majority of cases $(58.3 \%$, $15,501 / 26,601) .{ }^{5-7}$ From 2016 to 2018 , the case fatality ratio of P. falciparum malaria was 5.05 per 1,000 cases (29 deaths in 5,745 P. falciparum imported cases). ${ }^{6-8}$

The number of imported $P$. falciparum malaria cases has been rising in Hubei Province (from 28 in 2010 to 105 in 2014). ${ }^{9}$ Plasmodium falciparum malaria is challenging because of its potential of resulting in severe cases and death. Reducing severe cases and deaths caused by imported falciparum malaria is one of the important goals in Hubei Province. To better understand and address this challenge, we conducted a case-based epidemiological survey on each imported $P$. falciparum malaria case in Hubei Province and described their epidemiological profiles using data from the China Information System for Disease Control and Prevention (CISDCP) and Information System for Parasitic Disease Control and Prevention (ISPDCP) collected between 2013 and 2018. In addition, we identified risk factors associated with

\footnotetext{
*Address correspondence to Huaxun Zhang or Si Liu, Institute of Schistosomiasis Control, Hubei Provincial Center for Disease Control and Prevention, Zhuodaoquan North Road 35, Wuhan 430079, China. E-mails: huaxunzhang0707@163.com or liusi163@163.com
}

severe malaria to help improve measures aimed at the prevention and management of $P$. falciparum malaria.

\section{METHODS}

Malaria case definition. All $P$. falciparum malaria cases were confirmed through microscopy, rapid diagnostic tests, or polymerase chain reaction. In this study, we excluded cases of mixed infections of $P$. falciparum with other species from falciparum malaria cases. Only $P$. falciparum infections were included in the analysis. The definition of imported malaria was based on the technical scheme of malaria elimination in China definition, where an imported case is defined as an individual with malaria who traveled to a malaria-endemic area outside China within the previous month of disease onset. "Severe" $P$. falciparum malaria was defined based on previously described criteria ${ }^{2,10}: 1$ ) impaired level of consciousness, 2) prostration, 3) anemia (hemoglobin $<7 \mathrm{~g} / \mathrm{dL}$ and packed cell volume $<20 \%$ in adults), 4) renal impairment (serum creatinine $>265 \mu \mathrm{mol} / \mathrm{L}$ ), 5) pulmonary edema or acute respiratory distress syndrome, 6) hypoglycemia with blood glucose level $<2.2 \mathrm{mmol} / \mathrm{L}, 7$ ) circulatory collapse or shock (systolic blood pressure $<80 \mathrm{mmHg}$ in adults), 8) clinical jaundice, 9) hemoglobinuria, 10) acidosis (plasma bicarbonate $<15 \mathrm{mmol} /$ L), and 11) hyperlactatemia (plasma lactate level $>5 \mathrm{mmol} / \mathrm{L}$ ).

Data collection. Data on individual $P$. falciparum cases reported at the county level in Hubei Province during 2013-2018 were obtained from the CISDCP and ISPDCP. Extracted patient characteristics included gender, age, nationality, purpose of travel, history of malaria infection, symptom onset before or after return to China, month of symptom onset, time from onset to diagnosis, and the administrative level of first-visit medical institution. Clinical information on severe malaria was obtained from attending clinicians after extraction of the medical records.

Statistical analysis. Data were analyzed using SPSS version 16.0 (SPSS Inc., Chicago, IL). Categorical variables were reported as frequencies, whereas continuous variables were 
TABLE 1

Descriptive statistics of $P$. falciparum in Hubei Province, China, 2013-2018

\begin{tabular}{|c|c|c|c|c|c|c|c|}
\hline Characteristic & 2013 & 2014 & 2015 & 2016 & 2017 & 2018 & Total \\
\hline Total cases, $N$ & 129 & 140 & 120 & 151 & 96 & 127 & 763 \\
\hline P. falciparum (\% of total cases) & $86(66.7)$ & $105(75.0)$ & $91(75.8)$ & $103(68.2)$ & $49(51.0)$ & $94(74.0)$ & $528(69.2)$ \\
\hline $\begin{array}{l}\text { Number of counties with imported } P \text {. } \\
\text { falciparum cases }\end{array}$ & 31 & 40 & 35 & 41 & 26 & 40 & $77^{\star}$ \\
\hline $\begin{array}{l}\text { Severe cases of } P \text {. falciparum (\% of total } \\
\text { P. falciparum cases) }\end{array}$ & $11(12.8)$ & $9(8.6)$ & $10(11.0)$ & $10(9.7)$ & $4(8.2)$ & $7(7.4)$ & $51(9.7)$ \\
\hline Death number & 1 & 1 & 0 & 0 & 1 & 0 & 3 \\
\hline
\end{tabular}

reported as median and interquartile range (IQR). For categorical variables, the differences in characteristics between groups were tested using $x 2$ test. Logistic regression analysis was used to identify risk factors associated with severe malaria, and to estimate associated odds ratios (ORs) and corresponding $95 \% \mathrm{Cl}$. Only variables with $P$-values $<0.05$ were considered to be statistically significant. ArcGIS version 10.0 (ESRI Inc., Redlands, CA) was used to present the geographical distribution of $P$. falciparum cases.

Ethical considerations. This study was reviewed and approved by the Ethics Review Committee of the Hubei Provincial CDC. As the study was based on a retrospective review of disease reported data, informed consent was waived.

\section{RESULTS}

Epidemiological profiles of $\boldsymbol{P}$. falciparum cases. From 2013 to 2018, a total of 763 malaria cases were reported in Hubei Province. All the reported malaria cases were imported. Plasmodium falciparum was the most predominant species $(69.2 \%, 528 / 763)$ of all reported malaria cases, with the highest peak occurring in 2014 (105 cases) and the smallest in 2017 (49 cases). The proportion of malaria cases caused by $P$. falciparum increased from $66.7 \%$ in 2013 to $74.0 \%$ in 2018 (x2 = 21.378, $P<0.05)$. In 2018, a total of 127 imported malaria cases were reported, and $74.0 \%$ of them were identified as $P$. falciparum (Table 1). The number of counties with imported $P$. falciparum cases ranged from 31 to 41 per year; $P$. falciparum malaria cases were reported in 77 counties of Hubei (Figure 1). Of the patients with $P$. falciparum malaria, $9.7 \%(51 / 528)$ had severe malaria. The trend of proportion of patients with severe malaria from 2013 to 2018 was $12.8 \%$ (11/129), 8.6\% (9/140), $11.0 \%$ (10/120), 9.7\% (10/151), 8.2\% (4/96), and 7.4\% (7/127), respectively (Table 1). Three patients with $P$. falciparum malaria died (case fatality rate of $0.6 \%$ ), and all of them were men who had returned from African countries. The times from onset of symptoms to diagnosis were 7,8 , and 4 days (Table 2).

Region of infection acquisition for imported $\boldsymbol{P}$. falciparum cases. As shown in Figure 2, between 2013 and 2018, the 528 $P$. falciparum malaria cases imported into the Hubei Province were from 37 countries located in Africa, Asia, and South America. The largest number of imported cases was from Africa (98.9\%, 522/528), mainly from Nigeria (13.1\%, 69/528), Congo (Kinshasa) (12.3\%, 65/528), Angola (12.1\%, 64/528), Congo

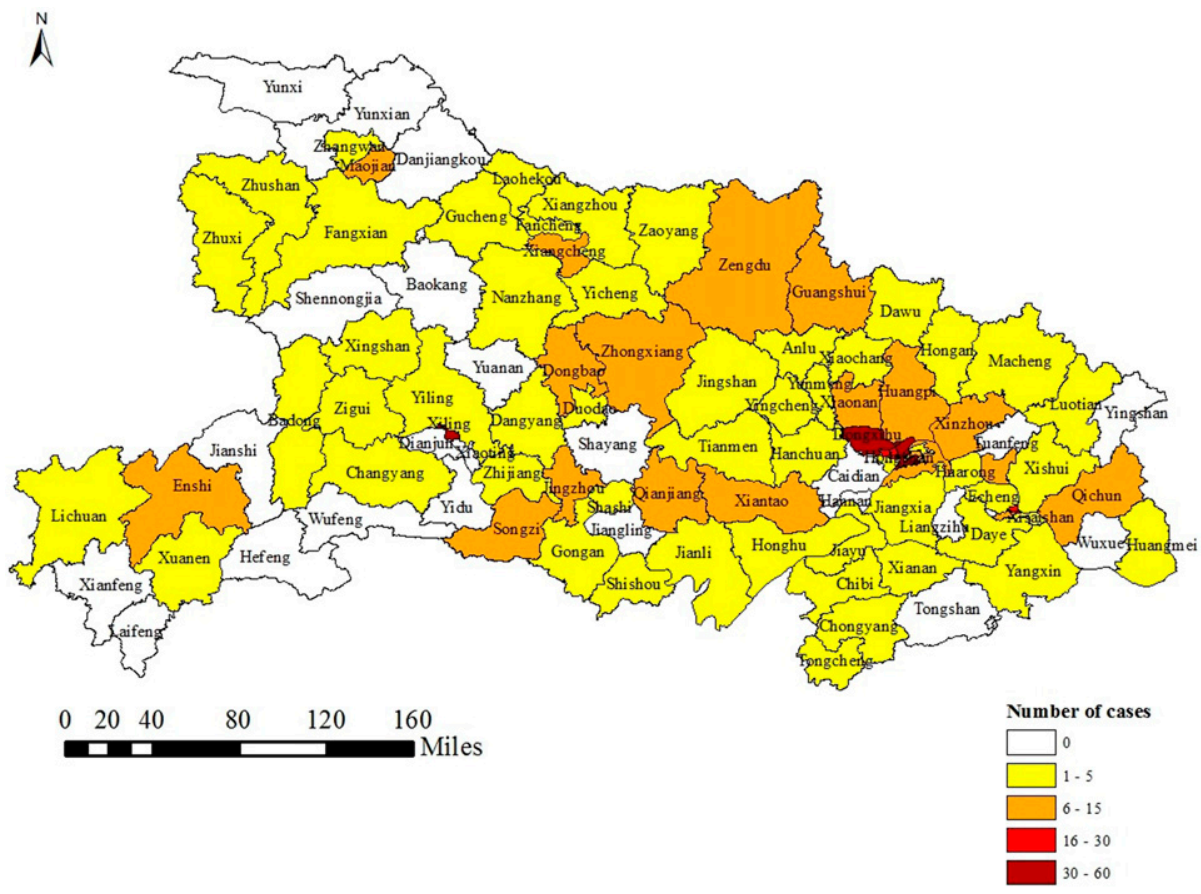

FIGURE 1. Distribution of imported Plasmodium falciparum malaria cases at the county level in Hubei Province from 2013 to 2018 . This figure appears in color at www.ajtmh.org. 
TABLE 2

Demographic characteristics of patients who died because of Plasmodium falciparum malaria

\begin{tabular}{|c|c|c|c|c|c|c|c|c|c|}
\hline \multirow[b]{2}{*}{ Case number } & \multirow[b]{2}{*}{ Year } & \multirow[b]{2}{*}{$\begin{array}{c}\text { Age } \\
\text { (years) }\end{array}$} & \multirow[b]{2}{*}{ Gender } & \multirow[b]{2}{*}{ Nationality } & \multirow[b]{2}{*}{ Travel purpose } & \multirow[b]{2}{*}{ Origin country } & \multicolumn{3}{|c|}{ Illness and diagnose } \\
\hline & & & & & & & Month of onset & $\begin{array}{l}\text { Time from onset to } \\
\text { diagnosis (days) }\end{array}$ & $\begin{array}{l}\text { The level of the first-visit } \\
\text { health institution }\end{array}$ \\
\hline 1 & 2013 & 30 & Male & Chinese & Labor & Congo (Kinshasa) & January & 7 & County hospital \\
\hline 2 & 2014 & 41 & Male & Chinese & Business & Mozambique & March & 8 & County hospital \\
\hline 3 & 2017 & 28 & Male & Chinese & Translator & Nigeria & October & 4 & Private clinics \\
\hline
\end{tabular}

(Brazzaville) (6.3\%, 33/528), Liberia (5.7\%, 30/528), and Ghana $(5.3 \%, 28 / 528)$. Of the 51 patients who had severe malaria, 98.0\% (50/51) had traveled to Africa.

Characteristics of patients with imported falciparum malaria in Hubei Province from 2013 to 2018. Characteristics of patients with imported $P$. falciparum malaria are shown in Table 3. Men were predominant in both non-severe $(97.1 \%$, $463 / 477)$ and severe cases $(92.2 \%, 47 / 51)$. The median age of non-severe and severe cases was $40(30-46)$ years and 40 (28-49) years, respectively. There was a significant difference in the proportion of patients aged $\geq 50$ years between non-severe and severe cases $\left(x^{2}=5.179, P<0.05\right)$. There were no significant differences between non-severe and severe cases with regard to gender, nationality, and travel purpose, symptom onset before or after return to China, and month of symptom onset $(P>0.05)$.

The median time from onset to diagnosis was 3 days $(\mathrm{IQR}=$ 3-6 days) for non-severe cases and 5 days (IQR $=3-9$ days) for severe cases; there was a significant difference in the proportion of cases with $>3$ days from onset to diagnosis between non-severe and severe cases $\left(x^{2}=10.000, P<0.05\right)$. There was a difference in the history of malaria infection $\left(X^{2}=5.539, P<0.05\right)$, and the proportion of first visits to medical institutions at a township level or lower $\left(x^{2}=12.212, P<0.05\right)$ (Table 3$)$.

Risk factors for severe malaria. Being female $(\mathrm{OR}=3.593$, 95\% Cl: $1.003-12.874)$, age $\geq 50$ years $(\mathrm{OR}=2.674,95 \% \mathrm{Cl}$ : 1.269-5.634), > 3 days between symptom onset and diagnosis (OR $=2.383,95 \% \mathrm{Cl}: 1.210-4.693)$, and the first-visit medical institution at the township level or lower $(\mathrm{OR}=2.568$, 95\% Cl: 1.344-4.908) were identified as risk factors for severe malaria. However, no significant association was found between severe cases and nationality, purpose of travel, no history of malaria infection, symptom onset before return to China, and month of symptom onset in January and February $(P>0.05)$ (Table 4).

\section{DISCUSSION}

The present study has identified changes in epidemiological characteristics of $P$. falciparum malaria imported over the past 6 years into Hubei Province, China. Plasmodium falciparum was the most predominant species imported. This situation is similar to the distribution of $P$. falciparum in China. ${ }^{4,5,11}$ Men and middleaged adults constituted most $P$. falciparum malaria cases during

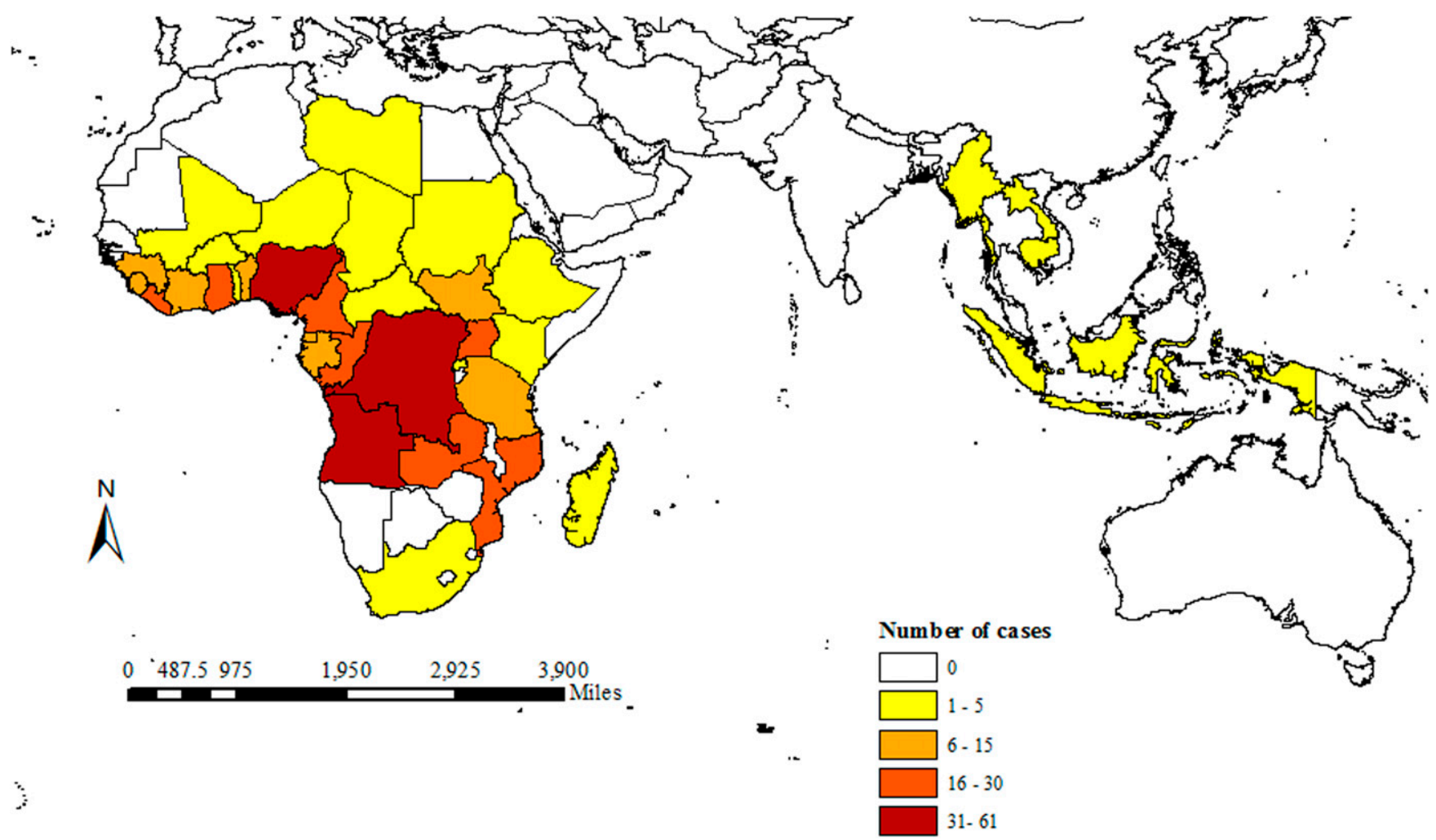

FIGURE 2. Imported Plasmodium falciparum malaria country of acquisition in Hubei Province during 2013-2018. This figure appears in color at www.ajtmh.org. 
TABLE 3

Characteristics of patients with imported P. falciparum malaria in Hubei Province from 2013 to 2018

\begin{tabular}{|c|c|c|c|c|c|}
\hline Variable & All $(n=528)$ & Non-severe $(n=477)$ & Severe $(n=51)$ & $x^{2}$ & $P$-value \\
\hline \multicolumn{6}{|l|}{ Gender, $n(\%)$} \\
\hline Male & $510(96.6)$ & $463(97.1)$ & 47 (92.2) & \multirow[t]{2}{*}{2.045} & \multirow[t]{2}{*}{0.153} \\
\hline Female & $18(3.4)$ & $14(2.9)$ & $4(7.8)$ & & \\
\hline \multicolumn{6}{|l|}{ Age (years) } \\
\hline Median (IQR) & $40(30-47)$ & $40(30-46)$ & $40(28-49)$ & & \\
\hline \multicolumn{6}{|l|}{ Age-group (years), $n$ (\%) } \\
\hline $0-49$ & $458(86.7)$ & 419 (87.8) & $39(76.5)$ & \multirow[t]{2}{*}{5.179} & \multirow[t]{2}{*}{0.023} \\
\hline$\geq 50$ & $70(13.3)$ & $58(12.2)$ & $12(23.5)$ & & \\
\hline \multicolumn{6}{|l|}{ Nationality, $n$ (\%) } \\
\hline Chinese & $515(97.5)$ & $465(97.5)$ & $50(98.0)$ & \multirow[t]{2}{*}{0.000} & \multirow[t]{2}{*}{1.000} \\
\hline Africa & $13(2.5)$ & $12(2.5)$ & $1(2.0)$ & & \\
\hline \multicolumn{6}{|l|}{ Travel purpose, $n(\%)$} \\
\hline Labor & $479(90.7)$ & $434(91.0)$ & 45 (88.2) & \multirow[t]{2}{*}{0.152} & \multirow[t]{2}{*}{0.697} \\
\hline Other* & $49(9.3)$ & $43(9.0)$ & $6(11.8)$ & & \\
\hline \multicolumn{6}{|c|}{ History of malaria infection, $n(\%)$} \\
\hline Yes & $319(60.4)$ & $296(62.1)$ & $23(45.1)$ & \multirow[t]{2}{*}{5.539} & \multirow[t]{2}{*}{0.019} \\
\hline No & $209(39.6)$ & $181(37.9)$ & $28(54.9)$ & & \\
\hline \multicolumn{6}{|l|}{ Symptom onset, $n(\%)$} \\
\hline Before return to china & $61(11.6)$ & $56(11.7)$ & $5(9.8)$ & \multirow[t]{2}{*}{0.169} & \multirow[t]{2}{*}{0.681} \\
\hline After return to china & $467(88.4)$ & $421(88.3)$ & 46 (90.2) & & \\
\hline \multicolumn{6}{|c|}{ Months of symptom onset, $n$ (\%) } \\
\hline $1-2$ & $115(21.8)$ & $104(21.8)$ & $11(21.6)$ & \multirow[t]{2}{*}{0.001} & \multirow[t]{2}{*}{0.969} \\
\hline $3-12$ & $413(78.2)$ & $373(78.2)$ & $40(78.4)$ & & \\
\hline \multicolumn{6}{|l|}{ Time from onset to diagnosis } \\
\hline Median (IQR) & $4(2-6)$ & $3(3-6)$ & $5(3-9)$ & & \\
\hline \multicolumn{6}{|l|}{ Group (days), $n$ (\%) } \\
\hline $0-3$ & $256(48.5)$ & $242(50.7)$ & $14(27.5)$ & \multirow[t]{2}{*}{10.000} & \multirow[t]{2}{*}{0.002} \\
\hline$>3$ & $272(51.5)$ & 235 (49.3) & $37(72.5)$ & & \\
\hline \multicolumn{6}{|c|}{$\begin{array}{l}\text { Administrative level of first-visit medical } \\
\text { institution, } n(\%)\end{array}$} \\
\hline Township level or lower & $108(20.5)$ & $88(18.4)$ & $20(39.2)$ & \multirow[t]{2}{*}{12.212} & \multirow[t]{2}{*}{0.000} \\
\hline County level or higher & $420(79.5)$ & $389(81.6)$ & $31(60.8)$ & & \\
\hline
\end{tabular}

${ }^{*}$ Other, including business and study.

the study period. This study indicated that travel to malariaendemic countries for work-related purposes might be the most important cause associated with imported malaria cases in Hubei. The main source of imported $P$. falciparum malaria in Hubei was Africa, where $P$. falciparum is highly endemic. Previous studies have indicated that the incidence of malaria was high among Chinese workers who had worked in African countries. ${ }^{12-16}$ Overseas workers generally lack immunity to $P$. falciparum species which is endemic in the new work area. ${ }^{17}$ In addition, workers tend to have insufficient knowledge and awareness regarding the risk of malaria infection. ${ }^{18}$ Thus, these workers should receive pretravel health advice as a matter of priority. Moreover, appropriate preventive measures, such as use of antimalaria chemoprophylaxis and personal protection measures against mosquito bites, should be enforced.

No indigenous cases of $P$. falciparum malaria have been reported since 1963 in Hubei Province. The first imported $P$. falciparum case was reported in $1999 .{ }^{19}$ During 2013-2018, imported $P$. falciparum malaria cases were reported in 77 counties of Hubei. In addition, the threat of $P$. falciparum drug resistance remains a problem for malaria treatment. ${ }^{20,21}$ Global warming can cause latitudinal and altitudinal shifts in vector distributions, thereby changing the risk of malaria. ${ }^{22}$ Imported $P$. falciparum malaria will continue to pose a challenge for eliminating malaria. Therefore, intensifying proactive surveillance systems and ensuring that the risk of transmission of $P$. falciparum is detected early are paramount to malaria elimination. ${ }^{4,23}$

Our analyses have indicated that four factors were associated with severe cases of $P$. falciparum malaria. The correlation between female gender and severe malaria found in this current study has not been reported in previous studies. ${ }^{24-26}$ The reasons for this result were likely due to the small sample size. Age $\geq 50$ years was a risk factor for severe malaria among imported $P$. falciparum cases. Previous studies have indicated that older age is a risk factor for severe imported $P$. falciparum malaria. ${ }^{26-28}$ This finding should prompt clinicians to advice travelers aged $\geq 50$ years on malaria prevention, and highlights the need for early diagnosis and treatment for patients with early symptoms of malaria. Time delay of $>3$ days between onset and diagnosis was associated with an increased risk of severe malaria in this study. Seringe et al. ${ }^{29}$ have reported that a time lapse of 4-12 days between the onset of symptoms and diagnosis of malaria was a risk factor for severe malaria. Some studies have also indicated that delays in diagnosis contribute to severe malaria. ${ }^{30,31}$ Early diagnosis is crucial for malaria control and treatment.

The first-visit medical institution at the township level or lower is likely to contribute to high numbers of severe malaria cases. This finding might be due to either lack of perceived risk and skills, or insufficient training provided by medical institutions at township and lower levels. Ding et al. ${ }^{32}$ have reported that the capacity for malaria diagnosis at institutions at township or lower levels was insufficient. Regular training and supervision of malaria diagnosis-related skills at institutions at township levels or lower should be emphasized in Hubei Province.

Lai et al. ${ }^{14}$ found higher case mortality rates in imported $P$. falciparum cases during January and February, a period that includes the Chinese New Year celebrations. Delayed 
TABLE 4

Factors associated with the risk of severity in Plasmodium falciparum malaria cases from 2013 to 2018

\begin{tabular}{lll}
\hline \multicolumn{1}{c}{ Variable } & \multicolumn{1}{c}{$\begin{array}{c}\text { Odds ratio } \\
(95 \% \mathrm{Cl})\end{array}$} & $P$-value \\
\hline Gender, female & $3.593(1.003,12.874)$ & 0.049 \\
Aged $\geq 50$ years & $2.674(1.269,5.634)$ & 0.010 \\
Nationality, Chinese & $2.082(0.202,21.448)$ & 0.538 \\
Travel purpose, labor & $0.740(0.250,2.190)$ & 0.587 \\
No history of malaria infection & $1.633(0.888,3.003)$ & 0.115 \\
Symptom onset before return to china & $0.696(0.256,1.891)$ & 0.477 \\
Month of symptom onset in January & $1.106(0.596,2.053)$ & 0.750 \\
$\quad$ and February & & \\
Time from onset to diagnosis > 3 days & $2.383(1.210,4.693)$ & 0.012 \\
First-visit medical institution at the & $2.568(1.344,4.908)$ & 0.004 \\
$\quad$ township level or lower & & \\
\hline
\end{tabular}

presentation to medical services and fewer medical staff on duty during the holiday might contribute to delayed diagnosis that results in a more severe malaria course. However, in our study, there was no significant association between risk of severe malaria and symptom onset in January and February.

Inability to assess factors such as educational level, parasite genetics, access to appropriate treatment, and antimalarial drug resistance, which are related to clinical outcomes of $P$. falciparum malaria, is considered a major limitation in this study. Future research should examine the contribution of these factors to the epidemiological profile of imported malaria cases in Hubei Province, China.

In conclusion, $P$. falciparum was the predominant imported plasmodium species. Imported $P$. falciparum malaria cases were reported in 77 counties of Hubei. Severe disease accounted for $9.7 \%$ of all $P$. falciparum cases. Risk factors for severe malaria were female gender, age $\geq 50$ years, $>3$ days between symptom onset and diagnosis, and the first-visit medical institution at the township level or lower. This research can further enrich knowledge and help provide valuable reference for the effective management of these cases in the future.

Received April 16, 2020. Accepted for publication June 17, 2020.

Published online July 20, 2020.

Acknowledgment: We thank all the staff in the county CDC in Hubei Province.

Financial support: This study was supported by the CDC of the Hubei Provincial Health and Family Planning Commission (Grant no. WJ2016J-037).

Authors' addresses: Jing Xia, Dongni Wu, Hong Zhu, Lingcong Sun, Wen Lin, Kaijie Li, Juan Zhang, Lun Wan, Huaxun Zhang, and Si Liu, Institute of Schistosomiasis Control, Hubei Provincial Center for Disease Control and Prevention, Wuhan, China, E-mails: xiaj0608@163.com, wudongnitiancai@hotmail.com, whzh2005@aliyun.com, 54996685@qq.com, 5078294@qq.com, 7856151@qq.com, 371092511@qq.com, 526177817@ qq.com, huaxunzhang0707@163.com, and liusi163@163.com. Kai Wu, Department of Schistosomiasis and Endemic Diseases, Wuhan City Center for Disease Prevention and Control, Wuhan, China, E-mail: cage2008@qq.com.

\section{REFERENCES}

1. WHO, 2019. World Malaria Report 2019. Geneva, Switzerland: World Health Organization.

2. WHO, 2012. Management of Severe Malaria. Geneva, Switzerland: World Health Organization.

3. Legros F et al., 2007. Risk factors for imported fatal Plasmodium falciparum malaria, France, 1996-2003. Emerg Infect Dis 13: 883-888.
4. Feng J, Zhang L, Huang F, Yin JH, Tu H, Xia ZG, Zhou SS, Xiao N, Zhou XN, 2018. Ready for malaria elimination: zero indigenous case reported in the People's Republic of China. Malar J 17: 315.

5. Lai SJ, Sun JL, Ruktanonchai NW, Zhou S, Yu JX, Routledge I, Wang LP, Zheng YM, Tatem AJ, Li ZJ, 2019. Changing epidemiology and challenges of malaria in China towards elimination. Malar J 18: 107.

6. Zhang L, Feng J, Zhang SS, Xia ZG, Zhou SS, 2018. The progress of national malaria elimination and epidemiological characteristics of malaria in China in 2017 [article in Chinese]. Chin J Parasitol Parasit Dis 36: 201-209.

7. Zhang L, Feng J, Zhao SS, Xia ZG, Zhou SS, 2019. Epidemiological characteristics of malaria and the progress towards its elimination in China in 2018 [article in Chinese]. Chin J Parasitol Parasit Dis 37: 241-247.

8. Zhang L, Feng J, Zhang SS, Jiang B, Xia ZG, Zhou SS, 2017. Malaria situation in the People's Republic of China in 2016 [article in Chinese]. Chin J Parasitol Parasit Dis 35: 515-519.

9. Xia J, Cai SX, Lin W, Pei SJ, Li KJ, Sun LC, Dong XR, Cao MM, Wu DN, Zhang HX, 2016. Epidemiological analysis of malaria prevalence in Hubei province from 2010 to 2014 [article in Chinese]. Chin J Schisto Control 28: 247-257.

10. National Health and Family Planning Commission of China, 2015. Diagnosis of malaria. Available at: http://www.nhc.gov.cn/ewebeditor/ uploadfile/2015/12/20151208094408183.pdf. Accessed December 8, 2015.

11. Zhou S, Li ZJ, Cotter C, Zheng CJ, Zhang Q, Li HZ, Zhou SS, Zhou $\mathrm{XN}$, Yu HJ, Yang WZ, 2016. Trends of imported malaria in China 2010-2014: analysis of surveillance data. Malar J 15: 39.

12. Wu HM, Fang ZQ, Zhao D, Chen YL, Liu CG, Liang X, 2017. A study on the epidemiological characteristics and infectious forecast model of malaria at Guangzhou airport among Chinese returnees from Africa. Malar J 16: 275.

13. Liu YB, Hsiang MS, Zhou HY, Wang WM, Cao YY, Gosling RD, Cao J, Gao Q, 2014. Malaria in overseas labourers returning to China: an analysis of imported malaria in Jiangsu province, 2001-2011. Malar J 13: 29.

14. Lai SJ et al., 2016. Plasmodium falciparum malaria importation from Africa to China and its mortality: an analysis of driving factors. Sci Rep 6: 39524.

15. Zhang SS, Feng J, Zhang L, Ren X, Geoffroy E, Manguin S, Frutos R, Zhou SS, 2019. Imported malaria cases in former endemic and non-malaria endemic areas in China: are there differences in case profile and time to response? Infect Dis Poverty 8: 61.

16. Xia J et al., 2018. Epidemiological characteristics of malaria from control to elimination in Hubei province, China, 2005-2016. Malar J 17: 81

17. Li ZJ et al., 2016. Epidemiologic features of overseas imported malaria in the People's Republic of China. Malar J 15: 141.

18. Zhang M, Liu ZY, He HT, Luo L, Wang SQ, Bu HL, Zhou X, 2011. Knowledge, attitudes, and practices on malaria prevention among Chinese international travelers. J Travel Med 18: 173-177.

19. Huang GQ et al., 2013. Potential infection of imported malaria and control measures in Hubei province [article in Chinese]. China Trop Med 13: 1490-1493.

20. Wu K et al., 2019. Analysis of Plasmodium falciparum $\mathrm{Na}(+) / \mathrm{H}(+)$ exchanger (pfnhe1) polymorphisms among imported African malaria parasites isolated in Wuhan, Central China. BMC Infect Dis 19: 354.

21. Yao $Y$ et al., 2018. Surveillance of genetic variations associated with antimalarial resistance of Plasmodium falciparum isolates from returned migrant workers in Wuhan, Central China. Antimicrob Agents Chemother 62: e02387-17.

22. Ren $Z P$ et al., 2016. Predicting malaria vector distribution under climate change scenarios in China: challenges for malaria elimination. Sci Rep 6: 20604.

23. Cao J, Sturrock HJ, Cotter C, Zhou SS, Zhou HY, Liu YB, Tang LY, GoslingRD, Feachem RG, Gao Q, 2014. Communicating and monitoring surveillance and response activities for malaria elimination: China's "1-3-7" strategy. PLoS Med 11: e1001642. 
24. Phillips A, Bassett P, Zeki S, Newman S, Pasvol G, 2009. Risk factors for severe disease in adults with falciparum malaria. Clin Infect Dis 48: 871-878.

25. Calleri G, Lipani F, Macor A, Belloro S, Riva G, Caramello P, 1998. Severe and complicated falciparum malaria in Italian travelers. J Travel Med 5: 39-41.

26. Schwartz E, Sadetzki S, Murad H, Raveh D, 2001. Age as a risk factor for severe Plasmodium falciparum malaria in nonimmune patients. Clin Infect Dis 33: 1774-1777.

27. Muhlberger $\mathrm{N}$ et al., 2003. Age as a risk factor for severe manifestations and fatal outcome of falciparum malaria in European patients: observations from TropNetEurop and SIMPID surveillance data. Clin Infect Dis 36: 990-995.
28. Saliba G, Kamouh W, Fontanet A, Le Bras J, 2011. Predictive factors of severe disease secondary to falciparum malaria among travelers. Pathol Biol (Paris) 59: 230-233.

29. Seringe E et al., 2011. Severe imported Plasmodium falciparum malaria, France, 1996-2003. Emerg Infect Dis 17: 807-813.

30. McCarthy AE, Morgan C, Prematunge C, Geduld J, 2015. Severe malaria in Canada, 2001-2013. Malar J 14: 151.

31. Cao YY, Wang WM, Zhou HY, Zhu GD, Xu S, Gu YP, Zhang C, Liu YB, Cao J, 2018. Cases diagnosis of imported malaria in Jiangsu province, 2014-2016 [article in Chinese]. Chin J Epidemiol 39: 218-221.

32. Ding GS et al., 2018. The challenge of maintaining microscopist capacity at basic levels for malaria elimination in Jiangsu province, China. BMC Public Health 18: 489. 